\title{
Influence of the material microstructural properties on a 3-point bending test
}

\author{
Ahmed Maati $^{1}$, Laurent Tabourot ${ }^{2,}{ }^{*}$, Pascale Balland ${ }^{3}$, and Salim Belaid ${ }^{4}$ \\ ${ }^{1}$ Mechanics Laboratory, Department of Mechanics, Laghouat University, Algeria \\ 2 Symme Laboratory, Savoie Mont Blanc University (EA4144), France \\ 3 Symme Laboratory, Savoie Mont Blanc University (EA4144), France \\ ${ }^{4}$ Mechanics Laboratory, Department of Mechanics, Laghouat University, Algeria
}

Received: 9 October 2019 / Accepted: 12 June 2020

\begin{abstract}
The purpose of this study is to highlight the role played by some important factors on sprinback phenomenon. This latter affects significantly the geometry of the manufactured product. Large automotive or plane body parts are specifically affected by this phenomenon which complicates the tools design. The study focuses here on specific materials with high trend to develop heterogeneous strains during forming processes. Due to its hexagonal crystalline structure, titanium has initial heterogeneous microstructure that grows stronger when plastic strain occurs. Heterogeneous microstructures induce the coexistence in the material of volumes with different mechanical properties even, in some case, with different mechanical behaviours. Therefore, accommodation between these volumes generates distributed internal stresses and important elastic energy storage. The macroscopic behaviour can be provided either by average phenomenological constitutive equation identical for all locations in the material or by integrating a set of local constitutive relations taking into account the variability of the behaviour as a function of the position in the material. In this context, experimental and numerical studies of a 3-point bending test on titanium alloy are considered.
\end{abstract}

Keywords: Bending test / springback / strain gradient / local behavior / heterogeneity

\section{Introduction}

Sheet metal forming is one of the most important manufacturing processes for mass production in industry. In these processes, plastic deformation is followed by some elastic recovery upon unloading called springback $(S B)$. This complex phenomenon is the geometric change during forming process and it affects the dimensional accuracy of a finished product [1]. $S B$ amount should be taken into consideration so as to produce bent sheet metal parts within acceptable tolerance limits [2]. This phenomenon depends both on process and material parameters such as die radius, sheet thickness, Young's modulus, etc. It has been analysed using different methods over the last few decades. In recent years the FEM is considered as an effective tool to predict $S B$ amount [3]. Various theoretical and numerical models have been proposed to predict $S B$ using tooling geometry and sheet metal properties [4-6]. Gardiner [7] derived a generalized mathematical analysis for $S B$ correction in the pure bending test. Panthi et al. [8]

\footnotetext{
* e-mail: laurent.tabourot@univ-smb.fr
}

proposed a phenomenological model for predicting $S B$ in arc bending operation by showing that, the amount of $S B$ is considerably influenced by the geometrical and the material parameters associated with the sheet metal.

Many analytical models proposed to study $S B$ in bending test use simple beam or plate bending theory. These models use simplified assumptions and do not provide error-free predictions $[9,10]$. Due to the increasingly intrinsic heterogeneous nature of thin metallic sheet, it is of greater interest to introduce heterogeneity parameters into the modelling of the mechanical behaviour [11]. Maati et al. [12] concluded that the results generated by the numerical simulations of $S B$ are more accurate if the material heterogeneities are considered.

Titanium alloys are excellent candidates for aerospace applications owing to their high strength to weight ratio and excellent corrosion resistance [13]. With a density of $4.5 \mathrm{~g} / \mathrm{cm}^{3}$, titanium alloys are only about half as heavy as steel or Ni-based super alloys [12]. However, parts made of titanium sheets present more $S B$ compared to parts made of steel. $S B$ occurs because of the elastic relief from the bending moment imparted to the sheet metal during forming [14]. The increase in elastic modulus and in strain 
hardening exponent leads to a decrease in $S B$ [15]. Due to its highly heterogeneous structure, titanium undergoes large elastic recovery during its formability [12].

In this paper, the 3-point bending test with $S B$ stage was systemically investigated by using numerical simulations. For comparison, two elastoplastic constitutive models are introduced in the finite element code. A comparison with experimental data has been made on strains thanks to the use of digital image correlation.

\section{Presentation of the two elastoplastic constitutive models}

In this study, two different types of phenomenological models were proposed to describe the elastoplastic behaviour of the material. The significant effect of microstructure on $S B$ was studied by using numerical simulations.

\subsection{Classical modelling}

In this case, the material is assumed to be homogeneous and isotropic. In the elastic range, the material behaviour is modelled by Young's modulus and Poisson's ratio. The reference curve between the yield stress and ultimate tensile stress can be described by an elastoplastic model with a von Mises plasticity criterion and isotropic hardening according to Hollomon's law. This later which is a power law relating the true plastic strain to the true stress is given by:

$$
\bar{\sigma}=K \bar{\varepsilon}_{p}^{n}
$$

$K$ and $n$ have been identified by fitting the numerical curve to data points. The reference curve will be used as input data in the finite element code.

\subsection{Hybrid modelling}

In this case, the material heterogeneity is considered in the modelling. Different factors determine the degree of material heterogeneity such as phases, subgrain and grain sizes, precipitates and gaps, etc. According to a study carried out by Tabourot et al. [11], materials with hexagonal structure are probably the most heterogeneous relative to other structures (e.g. CFC structure). This property significantly reduces the degree of material homogeneity which causes the dispersion in distribution of strains within the whole volume. One way to account for the heterogeneity is to assign to each element mesh a local behaviour law by using a probability distribution function [17]. The plastic behaviour is described by a bilinear rheological model according to the following relationship:

$$
\sigma=n_{h} \varepsilon_{p}+\sigma_{y}
$$

$\sigma y$ follows a Rayleigh's distribution that requires only one parameter $\sigma_{y m}$, it is comprised between a minimum value $\sigma_{0}$ and a saturation value $\sigma_{\text {sat }}[18]$. For the same distribution, $n_{h}$ and $\sigma_{s a t}$ are assumed to be constants at any point of the material.
Table 1. Chemical composition limits of the studied material.

\begin{tabular}{lllllll}
\hline Element & $\mathrm{O}$ & $\mathrm{N}$ & $\mathrm{C}$ & $\mathrm{H}$ & $\mathrm{Fe}$ & $\mathrm{Ti}$ \\
\hline Weight $(\%)$ & 0.20 & 0.05 & 0.1 & 0.013 & 0.25 & Bal. \\
\hline
\end{tabular}

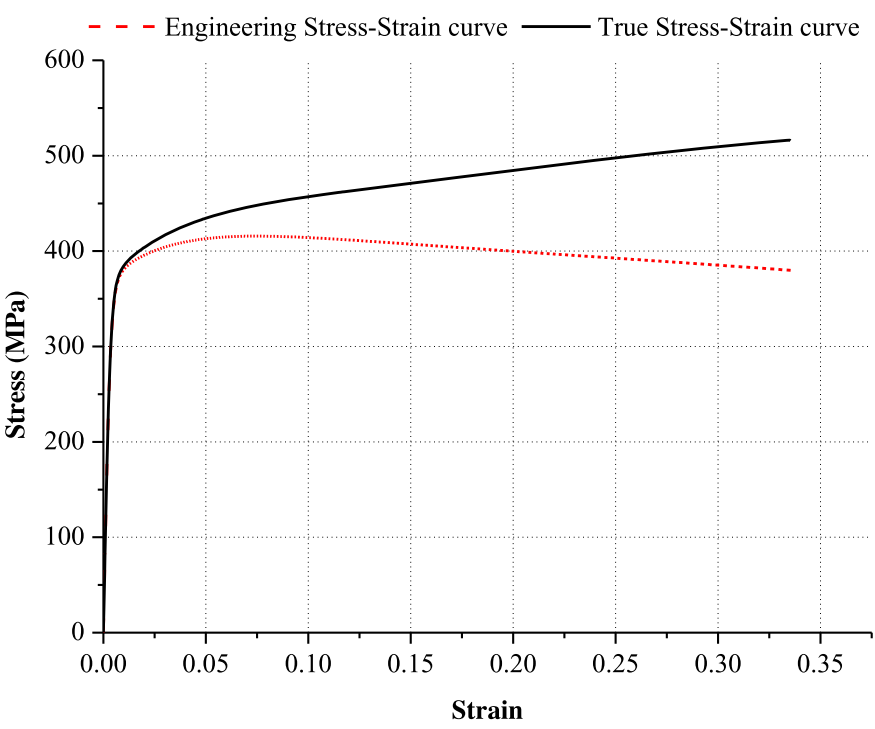

Fig. 1. Engineering and true stress-strain curves obtained along the RD.

\section{Experimental tests data}

\subsection{Material characterization}

The limits of the chemical composition of the titanium studied are given in Table 1.

Experimental data is of paramount importance in order to obtain reliable and accurate results. To characterize mechanical behaviour of the material studied, various tensile tests are carried out using INSTRON 5569 testing machine fitted with a load cell of $50 \mathrm{kN}$. These tests are performed on flat samples at a constant crosshead speed $V=7 \mathrm{~mm} / \mathrm{min}$. The size of the sample is $70 \times 14 \times 0.5$ $\left(\mathrm{mm}^{3}\right)$. An extensometer was used to measure the longitudinal strain. The difference between true and engineering stress-strain curves obtained along the rolling direction is illustrated in Figure 1.

In the elastic range, the material behaviour is characterized by Young's modulus $(E=110 \mathrm{GPa})$ and Poisson's ratio theoretically equal to 0.34 for titanium alloys.

\subsection{3-point bending test}

To investigate the influence of constitutive model in $S B$ prediction, the 3 -point bending test is proposed as a validation test. The device of the test is mounted properly on a tensile testing machine. The sample is placed on 2 supports and then centred on a bending punch. 


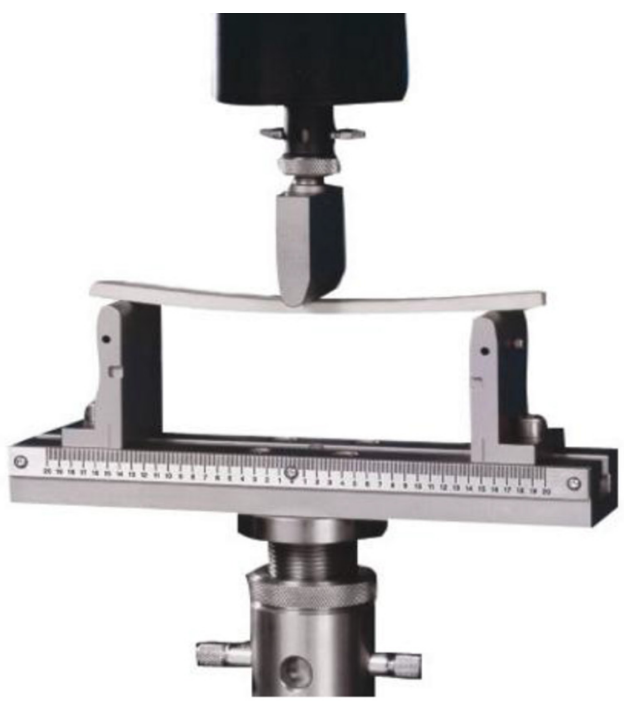

Fig. 2. The 3-point bending device.
The distance between supports is adjustable (40 $\mathrm{mm}$ in our case) as shown in Figure 2. The sample has the same dimensions as that of the tensile test. A speed of $7 \mathrm{~mm} / \mathrm{min}$ was imposed on the punch to carry out a progressive bending.

The strains of the samples were measured using a digital image analysis. Throughout the test, images were taken every second using a monochrome digital camera (type CMOS EoSens CL) with a resolution of $1280 \times 1024$ pixels. To have accurately the displacement amount of the punch, a pastille with random speckle pattern of black and white paint was glued to the punch as shown in Figure 3. The different steps of the 3-point bending test are also shown. In this test, the major objective is to evaluate the springback amount after removing the punch.

An area on the speckle pattern was analysed by software 7D [16] as shown in Figure 4. A vertical displacement $\mathrm{U} 2=8 \mathrm{~mm}$ is imposed to the punch. $7 \mathrm{D}$

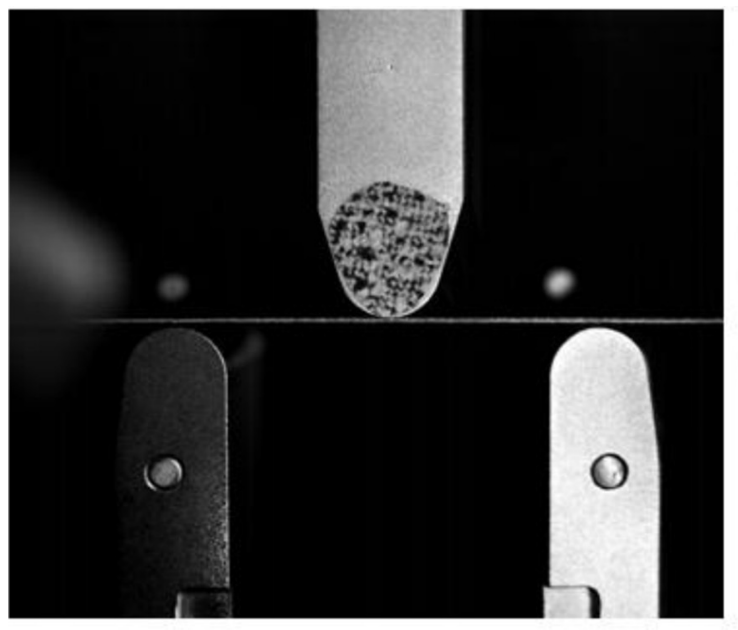

(a)

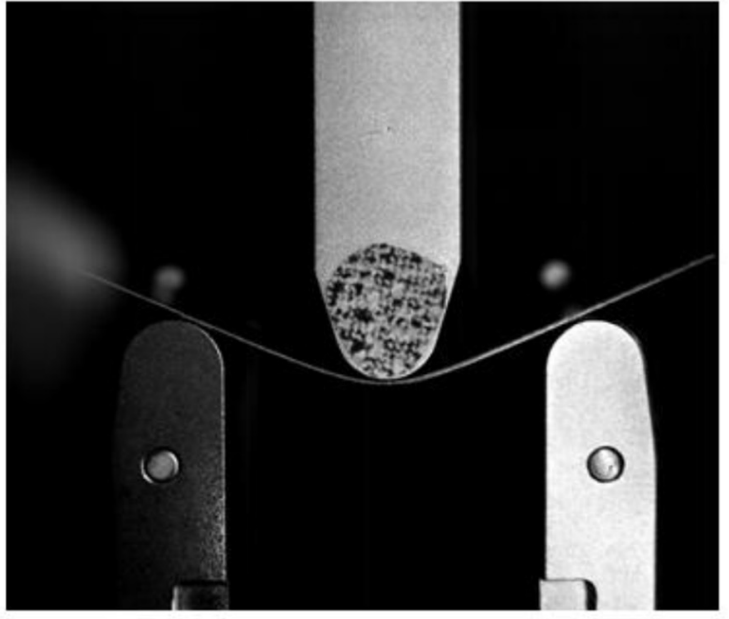

(b)

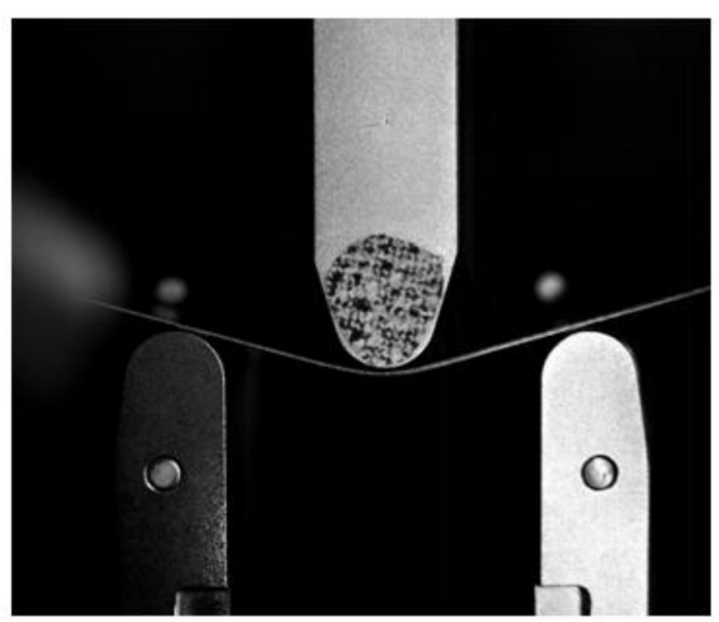

(c)

Fig. 3. Different steps of a 3-point bending test. (a) Start of the bending test (b) End of the bending test (c) $S B$ stage. 


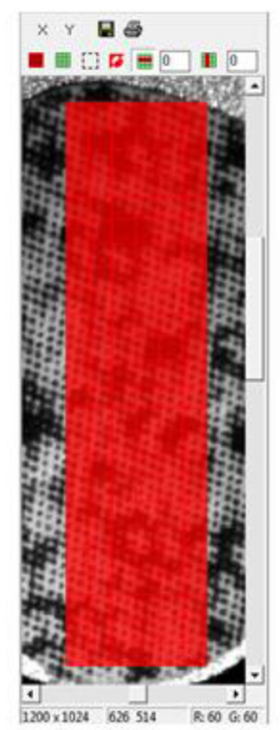

(a)

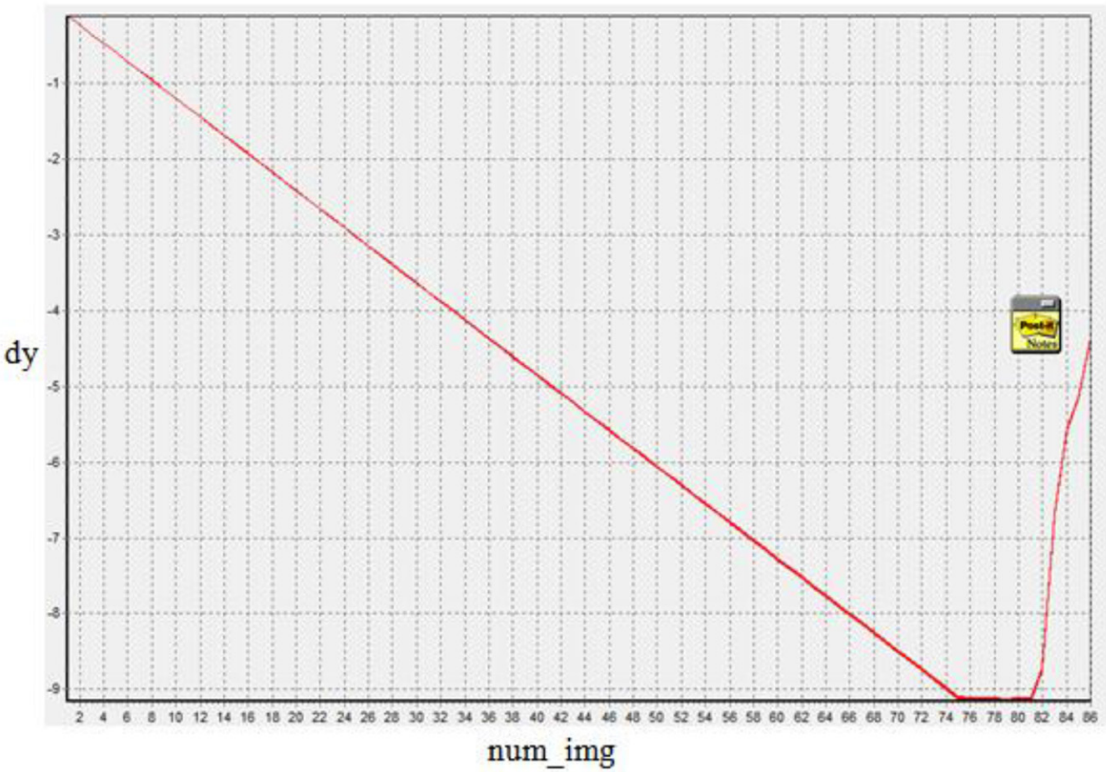

(b)

Fig. 4. Digital image analysis. (a) Area analyzed by software 7D. (b) Vertical displacement U2 versus image number.

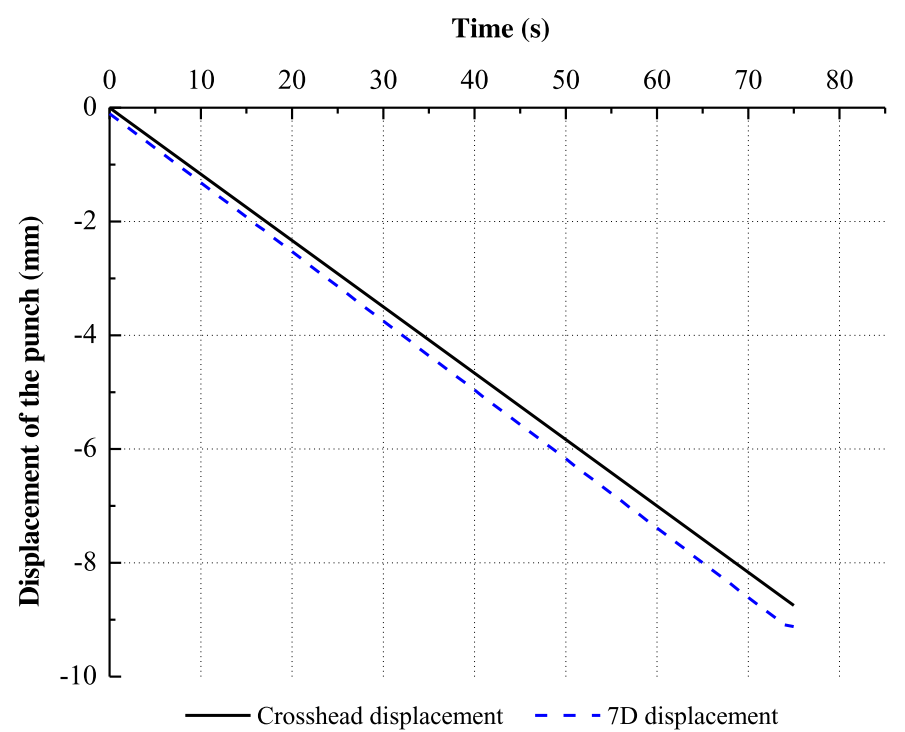

Fig. 5. Punch displacement as a function of time.

allows us to obtain multiple output results, for example, Figure 5 depicts the evolution of the punch displacement as a function of time. Perfect agreement is observed between the imposed displacement and the measured displacement using 7D software. Figure 6 gives the diagram of the load applied to the punch on the test piece as a function of the punch displacement. A comparative matching study between measurement data and numerical simulation will be conducted thereafter.

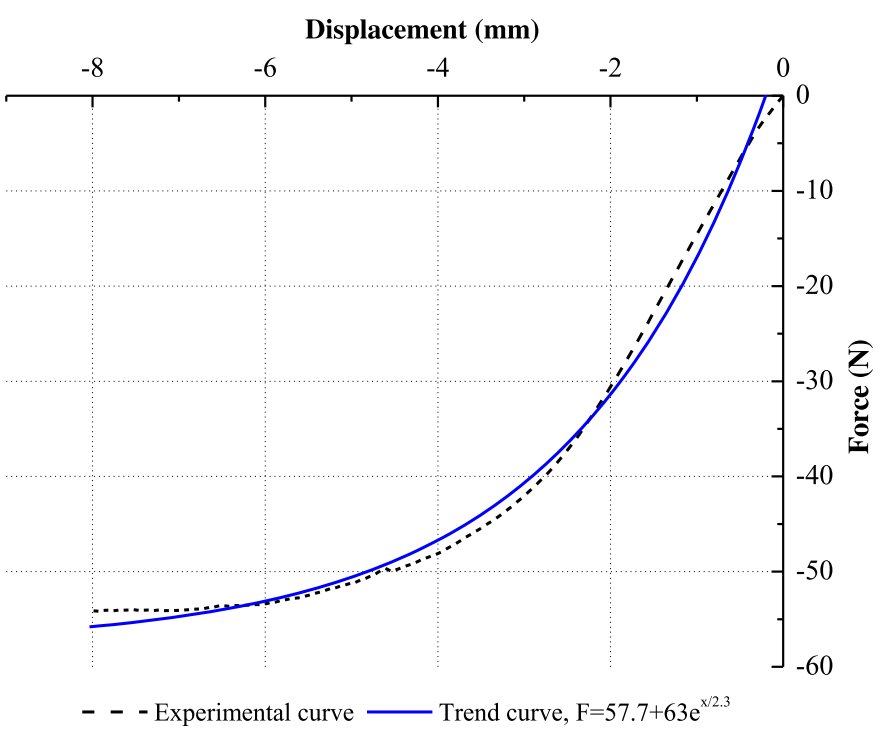

Fig. 6. Diagram force-displacement applied to the punch on the sample.

\section{Numerical simulation}

\subsection{Identification of the constitutive parameters for both models}

The first step of the FE simulation that integrates the material properties is to identify the parameters characterizing both models. These were identified 
Table 2. Constitutive parameters for both models.

\begin{tabular}{ll}
\hline Elastoplastic constitutive model & Parameters \\
\hline Hybrid model $(\mathrm{HM})$ & $\sigma_{y m}=770 \mathrm{MPa} ; n_{h}=600 \mathrm{MPa} ; \sigma_{\text {sat }}=1310 \mathrm{MPa}$. \\
Classical model $(\mathrm{CM})$ & $K=650 \mathrm{MPa} ; n=0.14$ \\
\hline
\end{tabular}

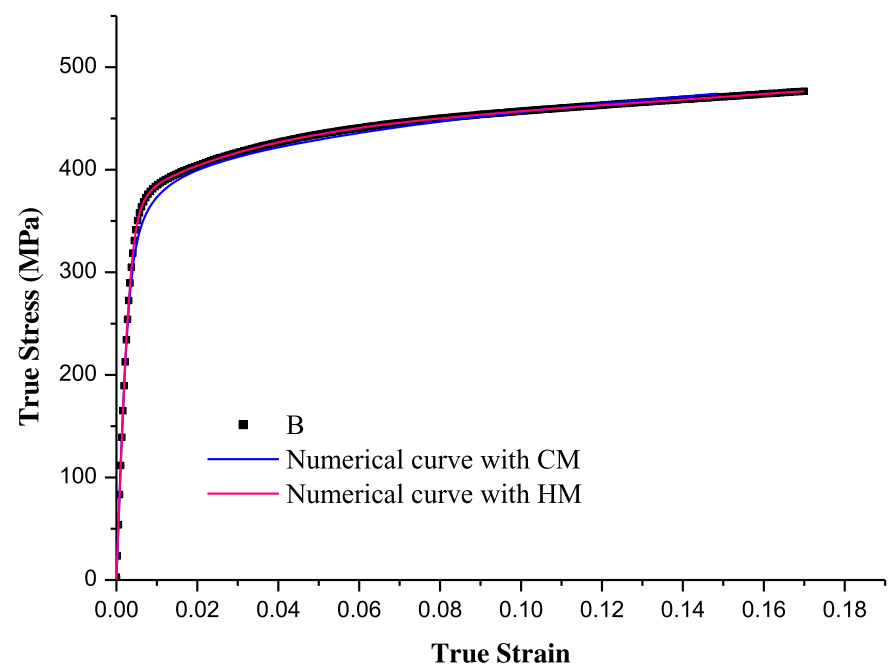

Fig. 7. Experimental and numerical true stress - strain curves obtained using both types of models.

by fitting the numerical curve to experimental data recovered from uniaxiale tensile test. As shown in Figure 7, the values listed in Table 2 give an acceptable agreement between experimental and numerical tensile curves for both types of models. Figure 8, for example, shows the deformation field on the surface of the specimen for both simulations (with and without considering the material heterogeneity).

\subsection{Numerical simulation of the 3-point bending test with $S B$ stage}

In order to reproduce results from experimental data, a FE simulation was carried out according to the experimental schematic and tooling data previously described. Firstly, a Classical model is considered. The mechanical behaviour of material is initially modelled by the elastic parameters ( $E$ and $v$ ) in the elastic range and by a reference curve according to the equation (1) in the plastic range of the tensile curve as shown in Figure 7.

The software Abaqus/Standard was used to setup the numerical model of 3-point bending test with $S B$ stage. The tools were assumed to be perfectly rigid. The part mesh which consisted of 9800 volume elements is obtained using C3D8R element type with 10 elements in the thickness. In order to take the different interactions between the rigid tools and the blank into account, a friction coefficient $(\mu=0.15)$ is proposed. Once the punch has done the prescribed displacement $\left(U_{2}=8 \mathrm{~mm}\right)$, the simulation removes the punch and the $S B$ will occur. For reasons of symmetry, only one-quarter of the test piece need to be modelled.The numerical description of the test is illustrated in Figure 9.

\section{Discussion of results}

In this work, we proposed and investigated two types of models to describe the elastoplastic behaviour of metals. Subsequently, the proposed models have been used to predict the $S B$ amount in a 3-point bending test. The incidence of material heterogeneity on $S B$ is also discussed by comparing numerical results with experimental measurements. To increase the probability of getting successful results, experimental data were obtained by the image analysis method. As shown in Table 3 , the $S B$ value for different methods is presented.

$\Delta x$ denotes the variation of the maximum deflection of the test piece before and after unloading.

According to the numerical simulation results, an acceptable agreement in terms of $S B$ amount is observed between simulation results based on a random distribution of mechanical properties within the material and experimental data. It has also been observed that the impact of material heterogeneity is less significant in the absence of kinematic hardening as long as the deformation direction is not reversed. This comparison showed an average relative error of less than $10 \%$. Furthermore, this error increases in the case using a conventional approach in which the error is about $13 \%$.

In addition, Figure 10 shows the distribution of the plastic equivalent strain along the selected paths. Path 1 is located in the centre of the test piece.

Figure 11a shows a side view (XY plane) of the test piece just at the end of the loading step. A set of 10 elements is depicted within a small distance $d x$ in the critical zone. As shown in Figure 11b, the material behaviour with classical model is characterized by two specific zones:

- Zone 1: the material behaviour is perfectly elastic, namely that the applied stress tends towards zero after discharge.

- Zone 2: residual stresses are generated after plastic deformation and a tendency to produce a more homogeneous stress distribution within the material. The elements of the set have almost the same elastic-plastic properties; however the final loading states reached are not the same for every element considered in the set.

If the material heterogeneities are introduced in the simulation, the stress distribution is very randomly, i.e. there are even elements not plasticized or relatively 


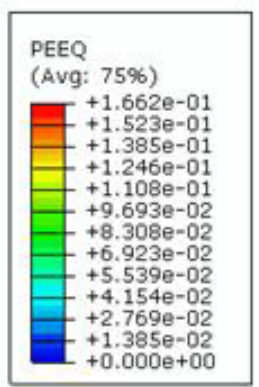

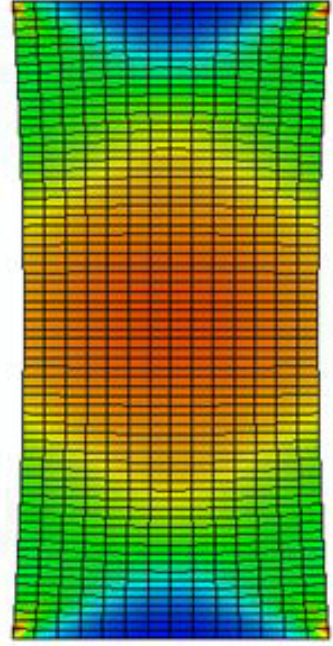

(a)

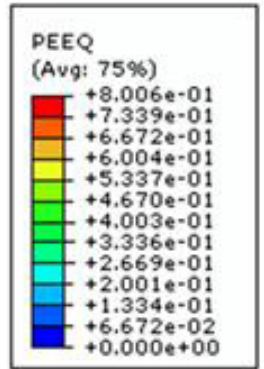

(b)

Fig. 8. Deformation field on the surface of the specimen for both simulations. (a) with classical model. (b) with hybrid model.
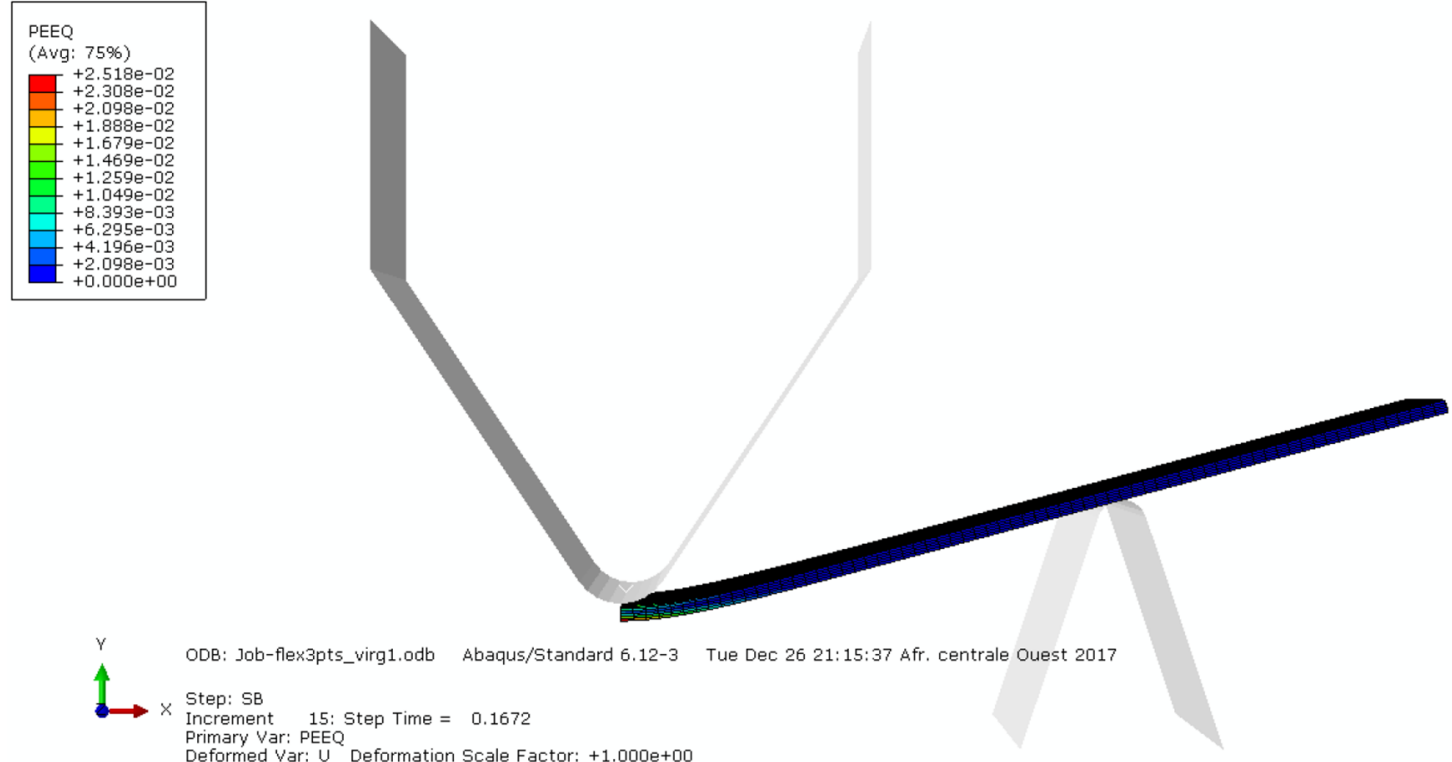

Deformy Var: $U$ Q Deformation Scale Factor: $+1.0000+00$
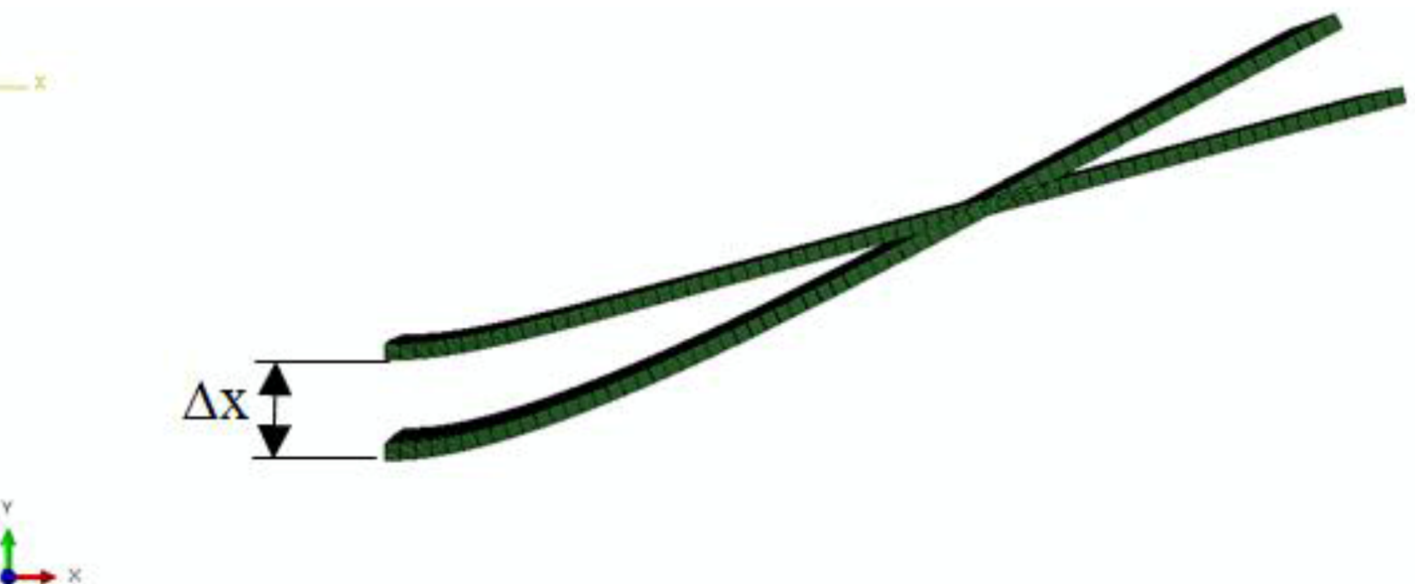

Fig. 9. Numerical description of the 3-point bending test with $S B$ stage. 
Table 3. $S B$ values obtained by the different methods.

\begin{tabular}{llll}
\hline Case considered & $\begin{array}{l}\text { Material heterogeneities } \\
\text { not included }\end{array}$ & $\begin{array}{l}\text { Material heterogeneities } \\
\text { included }\end{array}$ & $\begin{array}{l}\text { Experimental } \\
\text { measure }\end{array}$ \\
\hline$\Delta x(\mathrm{~mm})$ & 3.9 & 3.7 & 3.4 \\
\hline
\end{tabular}

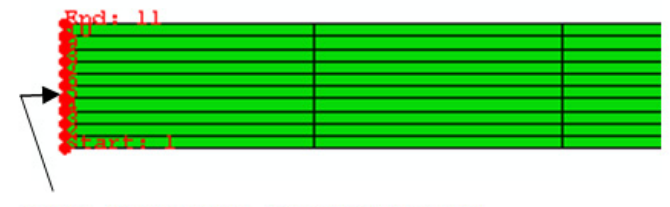

path 1 (across the sheet thickness)

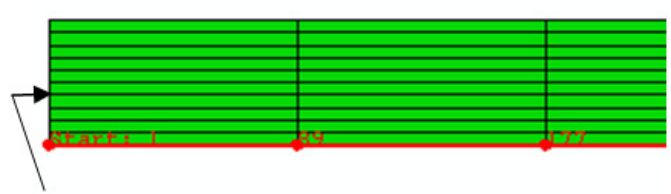

path 2 (along the length of the sheet)

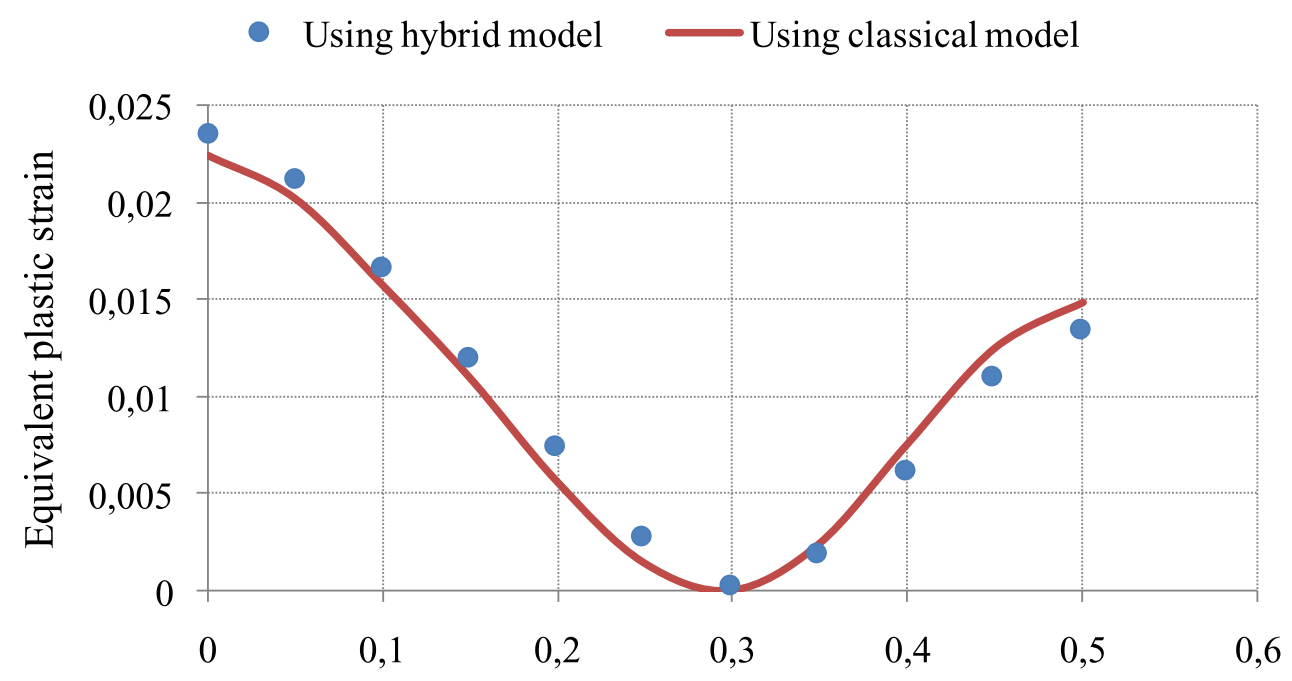

True distance across the sheet thickness ( $\mathrm{mm}$ )

(a)

- Using hybrid model —Using classical model

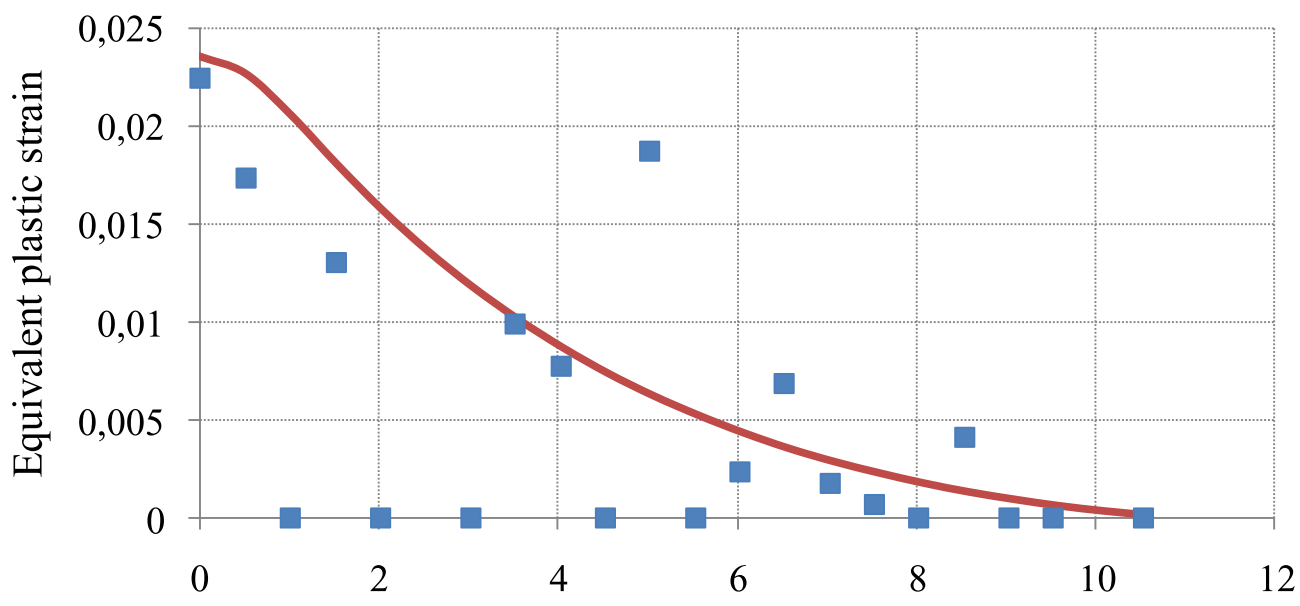

True distance along the length of the sheet $(\mathrm{mm})$

(b)

Fig. 10. Distribution of the plastic equivalent strain using both models. (a) across the sheet thickness (path1) (b) along the length of the sheet (path2). 


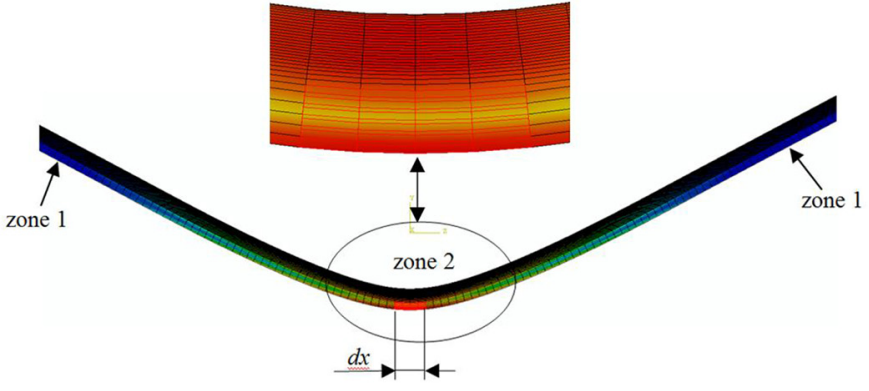

(a)

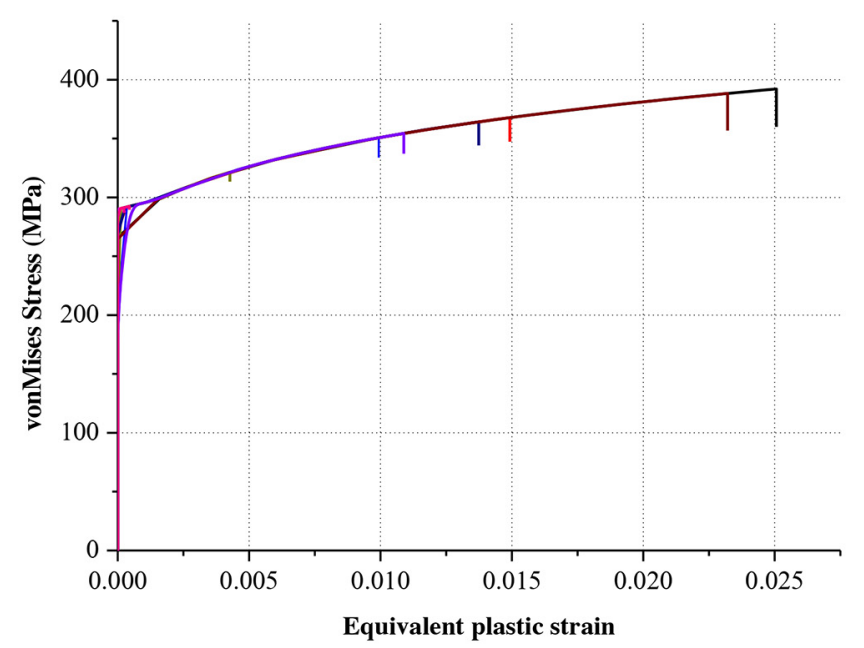

(b)

Fig. 11. State of stress without material heterogeneity. (a) Loading zones (b) Residual stresses in the zone 2.

plasticized in zone 2 . On the other hand, zone 1 may contain relatively plasticized elements. For example, Figure 12 shows the states of stress within the material for the set previously selected.

\section{Conclusion and perspective}

In this paper, two elastoplastic constitutive models have been proposed to characterize the elastoplastic behaviour of the studied material. The first is a classical model which assumes that the material properties are homogeneous within the whole volume of the sample, while the second is a hybrid model in which spatial heterogeneities are introduced using Rayleigh's distribution of hardening parameters. Then both were implemented into a finite element code which was used to predict $S B$ for 3 -point bending test. An experimental characterization of the material response using titanium sheets was performed in order to obtain the reference curve that will be used as input data in the FE code. A python script coupled to Abaqus is used to establish the identification of hardening parameters of both models. An acceptable convergence is observed between the numerical results using bilinear approach as a local law and the experimental measurement of $S B$, the error increases if the material heterogeneity is not included. Fine optimization of hardening parameters can effectively improve the numerical results.

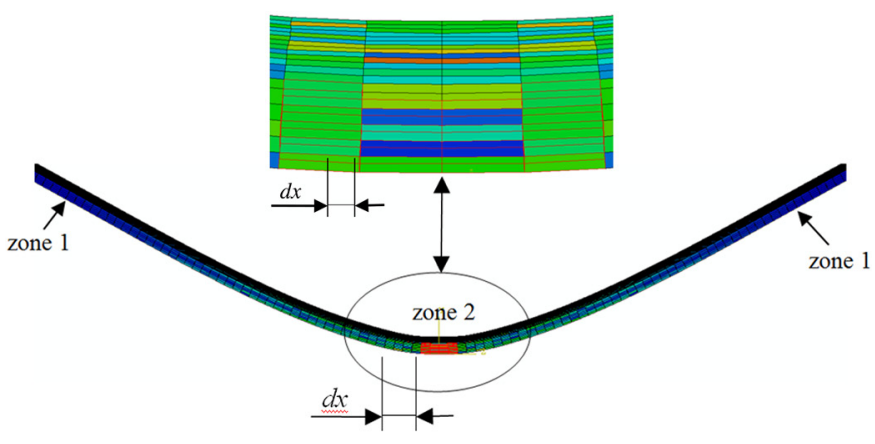

(a)

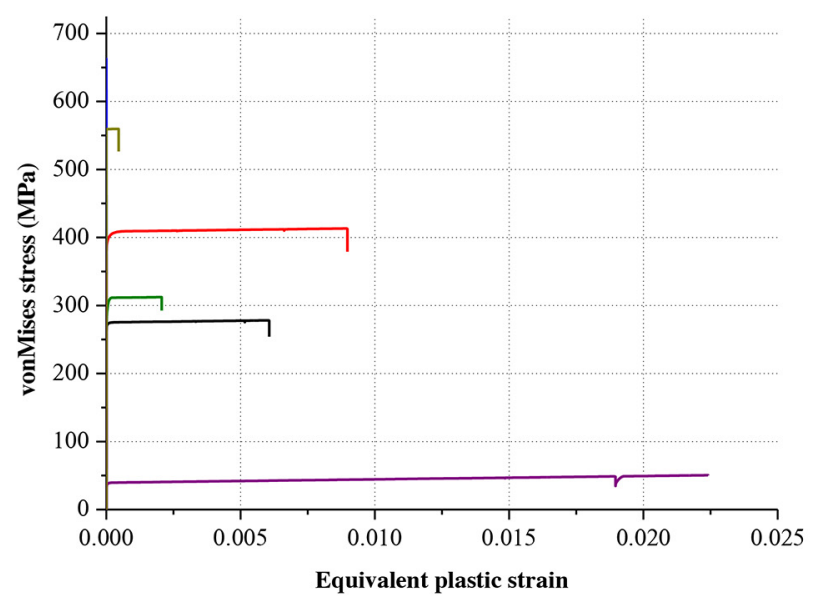

(b)

Fig. 12. States of stress with material heterogeneities. (a) Loading zones. (b) Residual stresses in the zone 2 (random distribution).

Finally, this type of physically based models will certainly be more effective to predict complex phenomena generated by the plastic deformation and which are more sensitive to the material heterogeneities such as the strain localization and kinematic hardening. It will be soon tested for complex path of deformation to check the potential of such a model.

The investigation of the effects of other parameters (type of mesh, choice of distribution function and local law, etc.) is still underway.

\section{Nomenclature}

$n_{h}(\mathrm{MPa}) \quad$ Hardening rate

$\sigma_{y}(\mathrm{MPa}) \quad$ Threshold stress

$\sigma_{y m}(\mathrm{MPa})$ Average yield stress

$\sigma_{\text {sat }}(\mathrm{MPa})$ Saturation stress

$\Delta x(\mathrm{~mm}) \quad$ Springback amount

\section{References}

[1] D. Pritima, P. Padmanabhan, Investigation of sheet bending parameters on springback in nickel coated mild steel sheets using response surface methodology, Mech. Ind. 19, 206 (2018) 
[2] W.M. Chan, H.I. Chew, H.P. Lee, B.T. Cheok, Finite element analysis of spring-back of V-bending sheet metal forming processes, J. Mater. Process. Technol. 148, 15-24 (2004)

[3] H.K. Yi, D.W. Kim, C.J. Van Tyne, Y.H. Moon, Analytical prediction of springback based on residual differential strain during sheet metal bending, Proc. Inst. Mech. Eng. C 222, 117-129 (2008)

[4] J.R. Cho, S.J. Moon, Y.H. Moon, S.S. Kang, Finite element investigation on springback characteristics in sheet metal U-bending process, J. Mater. Process. Technol. 141, 109-116 (2003)

[5] J.H. Jie, D.H. Liang, A novel model to predict U-bending springback and time-dependent springback for a HSLA steel plate, Int. J. Adv. Manufactur. Technol. 81, 1055-1066 (2015)

[6] A. Maati, V. Pouzols, L. Tabourot, P. Balland, E.H. Ouakdi, Numerical simulation of springback during an operation of V-bending, application to titanium and aluminum sheets, Adv. Mater. Res. 698, 69-78 (2013)

[7] F.J. Gardiner, The spring back of metals, Trans. ASME 1-9 (1957)

[8] S.K. Panthi, N. Ramakrishnan, A. Meraj Ahmed, S.S. Shambhavi, Finite Element Analysis of sheet metal bending process to predict the springback, Mater. Des. 31, 657-662 (2010)

[9] A.L. Castro, J.F. Durodola, N.A. Fellows, A closed form solution for predicting springback in bending of beams including hardening effect, Adv. Steel Construct. 5, 127-135 (2009)
[10] A. Queener, R.J. De Angelis, Trans. ASME 757 (1968)

[11] L. Tabourot, N.A. Sène, P. Balland, N. Ksiksi, L. Charleux, M. Issack, Comparative study of modelling efficiency regarding localization development, AIP Conf. Proc. 2017

[12] A. Maati, L. Tabourot, P. Balland, E.H. Ouakdi, M. Vautrot, N. Ksiksi, Constitutive modelling effect on the numerical prediction of springback due to a stretchbending test applied on titanium T40 alloy, Arch. Civil Mech. Eng. 15, 836-846 (2015)

[13] R.R. Boyer, An overview on the use of titanium in the aerospace industry, Mater. Sci. Eng. 1-2, 103-114 (1996)

[14] S.B. Chikalthankar, G.D. Belurkar, V.M. Nandedkar, Factors affecting on springback in sheet metal bending, Int. J. Eng. Adv. Technol. 3, 4 (2014)

[15] Z.Q. Jiang, H. Yang, M. Zhan, W.D. Xu, G.J. Li, Coupling effects of material properties and bending angle on the springback angle of titanium alloy tube during numerically controlled bending, Mater. Des. 31, 2001-2010 (2010)

[16] P. Vacher, S. Dumoulin, F. Morestin, S. Mguil-Toucha, Bidimensional strain measurement using digital images, J. Mech. Eng. Sci. 213, 811-817 (1999)

[17] T. Furushima, H. Tsunezaki, T. Nakayama, K. Manabe, S. Alexsandrov, Prediction of surface roughening and necking behaviour for metal foils by inhomogeneous FE material modelling, Key Eng. Mater. 554, 169-173 (2013)

[18] L. Tabourot, P. Balland, N.A. Sène, M. Vautrot, N. Ksiksi, A. Maati, Numerical study of the impact of constitutive modelling on the evolution of necking in the case of a tensile test on C68 grade steel, Key Eng. Mater. 611-612, 521-528 (2014)

Cite this article as: A. Maati, L. Tabourot, P. Balland, S. Belaid, Influence of the material microstructural properties on a 3-point bending test, Mechanics \& Industry 21, 518 (2020) 